\title{
Two new genera of Phoridae (Insecta: Diptera) from the Neotropical Region
}

\author{
BRIAN V. BROWN \& GIAR-ANN KUNG
}

Entomology Section, Natural History Museum of Los Angeles County, 900 Exposition Boulevard, Los Angeles, CA, 90007, USA.Email: bbrown@nhm.org, gkung@nhm.org

\begin{abstract}
Two new genera and species, Tapantia bicasa and Tayrona nitifrons, are described from Tapanti National Park, Costa Rica, and Tayrona National Park, Colombia, respectively. Tapantia bicasa is a basal lineage phorid of uncertain relationships, as it structurally resembles the genus Triphleba Rondani, but has male terminalia extremely similar to those of Dohrniphora Dahl. Tayrona nitifrons is highly unusual in many aspects, but especially in frontal setation, leg structure, wing structure, and male terminalia. It is classified in the subfamily Metopininae, although its precise relationships are unknown.
\end{abstract}

Key words: Diptera, Phoridae, new genus, Neotropical

\section{Introduction}

The phorid fauna of the Neotropical Region is still poorly known, but presumably the most diverse in the world. Recent revisionary papers by Brown (e.g. 1996, 1997, 2000, 2002, 2004) have documented huge numbers of undescribed Neotropical species, with many more expected in nearly all groups.

Even less well-described is the diversity at the genus level. This is in part because of difficulties in resolving the subfamily level classification of the family (Brown 1992; Disney 2003) and classifying the genera of subfamily Metopininae. Especially problematic are the Metopina-group of genera (sensu Brown 1992) and the large, probably paraphyletic genus Megaselia Rondani and its relatives. Our poor documentation of this fauna is also in large part because of insufficient resources of time and staff that can be focused on the problem of numerous specimens that are housed in the collection of our institution that do not fit into any current generic concepts. 
Until resources are available to address the significant problems described above, we intend to describe only the obviously highly distinctive taxa that are before us, such as the new genera and species described below.

\section{Tapantia new genus}

Type species: Tapantia bicasa new species.

Diagnosis. Frons lacking one pair of usual setae, either ventral fronto-orbital setae or supra-antennal setae. Frontal furrow absent. Anepisternum bare, lacking furrows (= undivided). Midtibia with basal pair of large, isolated setae; anterior subapical seta about as long as tibial width at point of its insertion. Hind tibia lacking dorsal, longitudinal setal palisade. Wing vein $\mathrm{R}_{2+3}$ absent, although there is some dark pigment in its usual position. Male epandrium with short ring basal to cerci, without long posterior epandrial projections.

Derivation of name. The name is based on the National Park at the type locality. Its gender is here considered to be feminine.

Phylogenetic Relationships. Tapantia is a non-metopinine genus, classified in what traditionally is considered the subfamily Phorinae. Although this genus is superficially similar to (and keys out near) Triphleba Rondani (in Disney 1994), the structure of the terminalia is much more similar to those of Dohrniphora Dahl (Figs. 3-4). Besides striking overall similarity, we propose that the presence of an epandrial ring links Tapantia with Dohrniphora, Diplonevra Lioy, Psyllomyia Loew, and some other genera (as outlined by Brown, 1992). These genera were placed in a tribe Diplonevrini by Brown (1992) within his revised subfamily Aenigmatiinae, but this classification, like others within the family, requires extensive further data and evaluation. Discovery of the female of this genus would be particularly welcome and informative.

Recognition. This species keys to couplet 76 in the latest key to phorid genera (Disney 1994), where we are asked to choose between wing vein $\mathrm{R}_{2+3}$ complete (genus Triphleba Rondani, in part) versus wing vein $R_{2+3}$ basally obliterated. In either case, at least a vestigial $R_{2+3}$ is expected, whereas in Tapantia there is only some dark pigment. If we take lead 2 , we are lead to couplet 77. The two leads of couplet 77 are "Restricted to New Zealand" versus "Restricted to Holarctic Region," neither of which apply. The first lead is for the genus Kierania Schmitz, which differs from Tapantia by having elongate posterior processes on the epandrium. The second lead is for Triphleba, in part, which also has such elongate processes. Interestingly, undescribed Neotropical Region species of Triphleba Rondani that completely lack wing vein $\mathrm{R}_{2+3}$ also key to this problematic couplet. To amend these problems, we propose the following modification to Disney's key: 
76. Fork of vein 3 complete [ $=\mathrm{R}_{2+3}$ fully developed].

77. Male terminalia with posterodorsal area of epandrium narrow, continuous below cerci, not produced posteriorly; cerci relatively elongate, base of cerci with short epandrial ring Tapantia

- Male terminalia with posterodorsal area of epandrium produced posteriorly, ending freely, often in elongate processes; cerci short, base of cerci without epandrial ring..

$77 \mathrm{~A}$

77A. Restricted to New Zealand Kierania

- $\quad$ Restricted to Holarctic and Neotropical Regions Triphleba (part)

\section{Tapantia bicasa new species}

Figs. 1-4.

Description. Body length $2.2 \mathrm{~mm}$. Wing length $2.4 \mathrm{~mm}$. Frons (Fig. 1) subequal in height and width, dark brown, with 12 large, relatively long (especially postocellar) setae. Homology of setae on ventral half of frons unknown; either 1) supra-antennal setae absent and their place occupied by ventral interfrontal setae, with ventral fronto-orbital setae displaced away from eye margin near midline, or 2) ventral fronto-orbital setae absent and one pair of divergent, dorsally-directed supra-antennal setae present. Flagellomere 1 dark brown, oval, slightly pointed apically, arista subapical. Palpus dark brown, with numerous setae and prominent white sensilla. Proboscis yellow, slightly elongate. Thorax dark brown; scutal setae elongate. Notopleural cleft absent. Scutellum triangular, with short outer pair and long inner pair of setae. Anepisternum without furrows, bare; spiracle large. All legs elongate, yellow-brown, except apex of hind femora gradually darkened. Tibiae without dorsal, longitudinal setal palisades. Foretibia with 1 long anterodorsal seta slightly basal to midlength. Midtibia with basal pair of longer anterodorsal and shorter posterodorsal setae and one anterior seta near apex that is slightly longer than width of tibia at its insertion; midtibia also with three dorsal, transverse combs of setae (ctenidia) on apical one-third, although they are not as heavily sclerotized as in other phorids possessing such ctenidia (e. g. Hypocera Lioy, some Chaetopleurophora Schmitz); apical to ctenidia is small, dorsal, bare area. Hind tibia with long anterodorsal seta at basal one-third and small anterior seta near apex. Inner face of hind femur unmodified. Wing (Fig. 2) with short costal setae. Wing vein $\mathrm{R}_{2+3}$ absent, although dark pigment present in its usual place. Base of Rs with one seta. Halter dark brown. Abdominal tergites dark brown. Venter of abdomen gray, setose. Male terminalia (Fig. 3-4) dark brown, with epandrial ring at base of cerci; epandrium otherwise continuous below cerci. Left lobe of hypandrium with large, curved excision (Fig. 3). Right side of epandrium with large posterior seta (Fig. 4). Cerci relatively long; hypoproct broad in ventral view; both cerci and hypoproct dark brown. 
Holotype. ${ }^{\star}$, COSTA RICA: Cartago: Tapanti, $9.78^{\circ} \mathrm{N}, 83.78^{\circ} \mathrm{W}, 17-20 . v i i .2000, \mathrm{~S}$. Ashe, R. Brooks, FIT \#192, 1200m [barcode label: LACM ENT 072941]. Deposited in Natural History Museum of Los Angeles County.
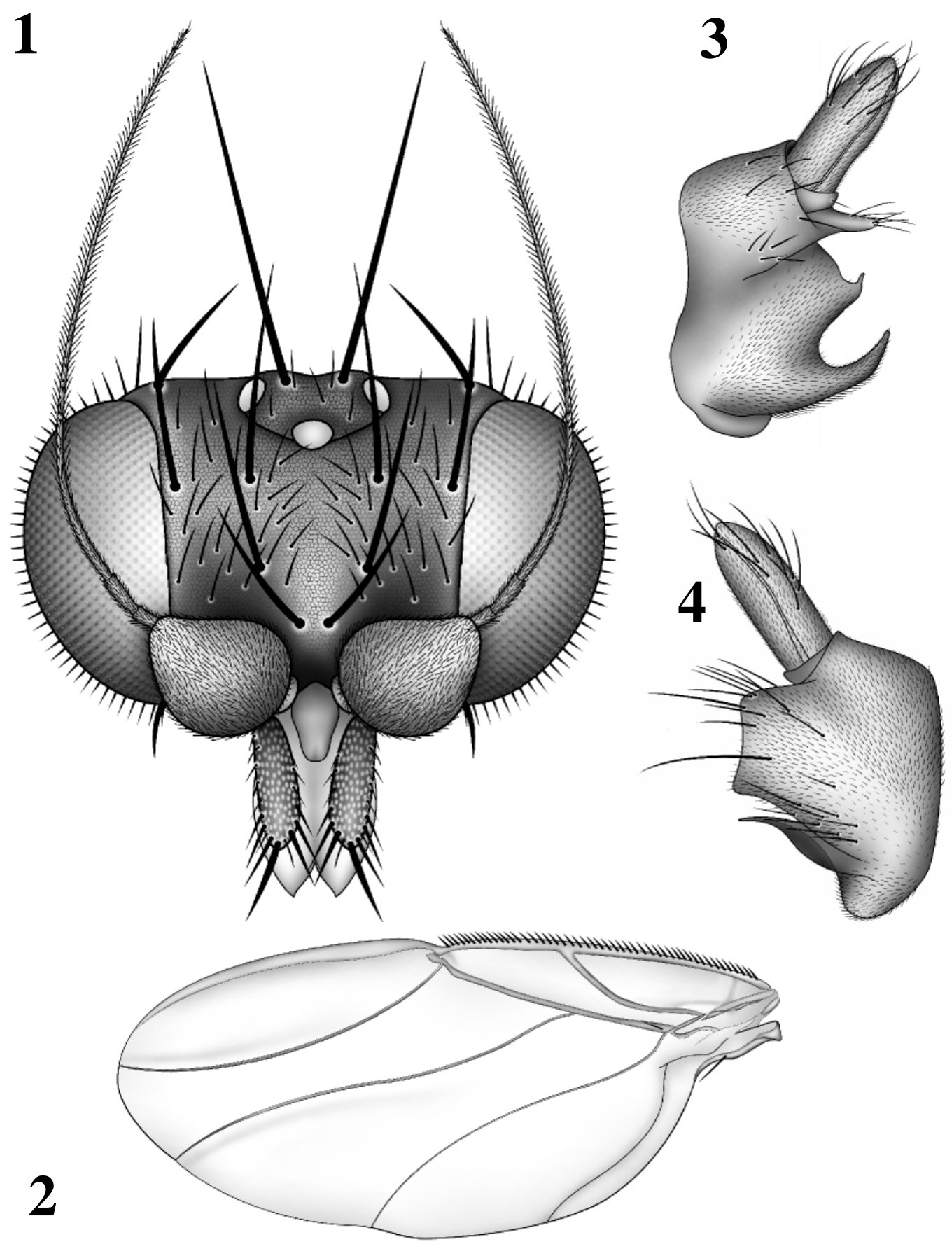

FIGURES 1-4. Tapantia bicasa new species. 1. Head. 2. Wing. 3. Male terminalia, left side. 4. Male terminalia, right side. 

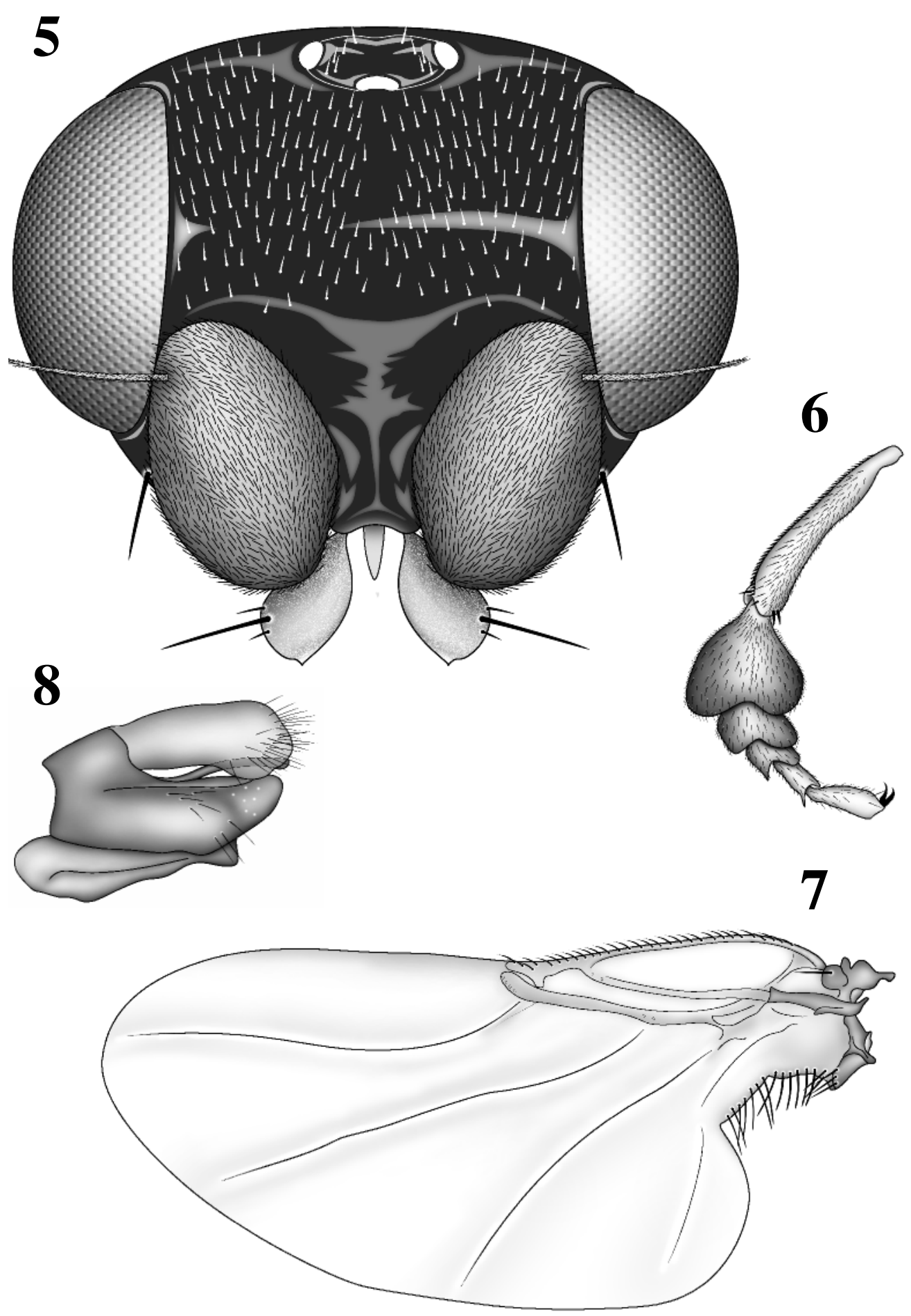

FIGURES 5-8. Tayrona nitifrons new species. 5. Head. 6. Foretibia and tarsomeres. 7. Wing. 8. Male terminalia, left side. 
Type species: Tayrona nitifrons new species.

Diagnosis. Frons broad, shining black, lacking setae. Foretarsomeres 1-3 greatly enlarged. Tibiae of all legs with dorsal, longitudinal setal palisade; lacking large, isolated setae. Costal margin of wing basally convex.

Derivation of name. The name is that of the National Park at the type locality, which is in turn based on the name of the ancient culture of the indigenous people living there. Its gender is here considered to be feminine.

Phylogenetic Relationships. Based on the divided anepisternum and lack of tibial setae, this genus is classified in the subfamily Metopininae. Its body structure is highly unusual in many respects, however, and its relationships within this subfamily are unknown.

Recognition. In the latest key to phorid genera (Disney 1994), Tayrona does not key satisfactorily because the presence of $\mathrm{R}_{2+3}$ (= vein 3 forked) is equivocal. It runs to couplet 88 , where we are forced to accept the first lead $\left(\mathrm{R}_{2+3}\right.$ present) because other characters in the second lead do not match. If we accept that $\mathrm{R}_{2+3}$ is present in the later couplet 90 , Tayrona differs from all other genera by the lack of frontal setae. It is a highly distinctive genus, however, and unlikely to be confused with any other phorid.

\section{Tayrona nitifrons new species}

Description. Male. Body length $2.4 \mathrm{~mm}$, wing length $1.6 \mathrm{~mm}$. Frons (Fig. 5) broad, glossy black, shining, with small setulae only, lacking all usual frontal and vertical setae. Antennal flagellomere 1 enlarged, elongate-oval; arista relatively short, inserted subapically and laterally. Palpus yellowish-brown, short, rounded, with one large seta and several smaller ones. Proboscis vestigial, less than one-half length of palpus, probably non-functional. Thorax dark brown; setae of scutum greatly reduced in size. Notopleural cleft absent. Scutellum short, broad, with 4 long setae, inner pair $0.5 \mathrm{~mm}$, outer pair $0.4 \mathrm{~mm}$ long. Anepisternum with vertical furrow, posterior portion with several short setae dorsally. Usual position of horizontal anepisternal furrow located at lateral margin of scutum, such that spiracle deflected to dorsum of scutum; spiracle large. All legs yellow-brown, relatively short. Tibiae with dorsal, longitudinal setal palisade that is deflected anteriorly at apex, without anterior or posterior row of differentiated setae. Forefemur with slightly differentiated posterior seta near apex. Foretarsomeres 1-3 greatly enlarged (Fig. 6), dark brown. Tarsomere 1 of mid- and hind leg slightly darkened. Basal costal margin of wing strongly convex (Fig. 7), such that humeral crossvein is at 45 degree angle to longitudinal axis of wing. Anal region of wing strongly developed, but constricted basally; axillary margin 
with numerous setae. Costal setae short. All wing veins lightly sclerotized and difficult to see. Wing vein Sc not visible, even with slide mounting and phase contrast lighting. Wing vein $R_{2+3}$ incomplete or absent, although costa thickened in the area where it usually occurs. Apex of vein $\mathrm{R}_{4+5}$ slightly thickened. Vein Rs with slight ventral thickening at origin of vein M2. Halter dark brown. Abdominal tergites matte dark brown, except tergites 4-6 glossy, shiny. Abdominal venter gray, bare. Terminalia (Fig. 8) dark brown, approximately symmetrical. Epandrium elongate posteriorly, with raised lateral area. Hypandrium and aedeagal structure not observed in detail. Cercus yellow, large, with small setae; with lateral lobe-like projection subapically. Hypoproct elongate, narrow.

Female. Unknown.

Holotype. ${ }^{x}$, COLOMBIA: Magdalena: PNN Tayrona, Zaino, $11.33^{\circ} \mathrm{N}, 74.03^{\circ} \mathrm{W}$, 29.i-21.ii.2001, R. Henriquez, Malaise trap, CAP-1349, 50 m [barcode label: LACM ENT 180789]. Deposited in Museo de Historia Natural, Instituto de Ciencias Naturales, Universidad Nacional de Colombia, Bogotá.

\section{Acknowledgments}

We thank the staff of the Colombian Arthropod Survey at the Humboldt Institute, Villa Leyva, Colombia, for their hard work in sorting samples, and Rob Brooks for sending us unsorted flight intercept trap samples. The figures were expertly prepared by Lai Shan Mui, who was supported by the United States National Science Foundation (NSF) grant DEB-0090031 to B. Brown. Research in Colombia was funded by NSF grants DEB9972024 and DEB-0205982 to M. Sharkey and B. Brown.

\section{References}

Brown, B.V. (1992) Generic revision of Phoridae of the Nearctic Region and phylogenetic classification of Phoridae, Sciadoceridae and Ironomyiidae (Diptera: Phoridea). Memoirs of the Entomological Society of Canada, 164, 1-144.

Brown, B.V. (1996) Preliminary analysis of a host shift: revision of the Neotropical species of Apocephalus, subgenus Mesophora (Diptera: Phoridae). Contributions in Science, No. 462, 1-36.

Brown, B.V. (1997) Revision of the Apocephalus attophilus-group of ant-decapitating flies (Diptera: Phoridae). Contributions in Science, No. 468, 1-60.

Brown, B.V. (2000) Revision of the "Apocephalus miricauda-group" of ant-parasitizing flies (Diptera: Phoridae). Contributions in Science, No. 482, 1-62.

Brown, B.V. (2002) Revision of the Apocephalus pergandei-group of ant-decapitating flies (Diptera: Phoridae). Contributions in Science, No. 496, 1-58.

Brown, B.V. (2004) Revision of the subgenus Udamochiras of Melaloncha bee-killing flies (Diptera: Phoridae: Metopininae). Zoological Journal of the Linnean Society, 140, 1-42.

Disney, R.H.L. (1994) Scuttle flies—the Phoridae. Chapman \& Hall, London, 467 pp.

Disney, R.H.L. (2003) The dorsal abdominal glands and the higher classification of the Phoridae (Diptera). Zootaxa, 293, 1-16. 